\title{
An in situ AFM Study of the Evolution of Surface Roughness for Zinc Electrodeposition within an Imidazolium Based Ionic Liquid Electrolyte
}

\author{
Jayme S. Keist ${ }^{\mathrm{a}, \mathrm{b}, 1}$, Christine A. Orme ${ }^{\mathrm{c},}$, Paul K. Wright ${ }^{\mathrm{d}}$, and James W. Evans ${ }^{\mathrm{e}}$ \\ a 210 Hearst Mining Building, University of California, Berkeley, CA USA 94720 \\ Email: jkeist@berkeley.edu \\ ${ }^{\mathrm{b}}$ Lawrence Livermore National Laboratory, 7000 East Ave. Livermore, CA 94550 USA \\ ${ }^{\mathrm{c}}$ Lawrence Livermore National Laboratory, 7000 East Ave. Livermore, CA 94550 USA \\ Email: orme1@1lnl.gov
}

Phone: 1 (925) 423-9509

d 330C Sutardja Dai Hall, University of California, Berkeley, CA 94720 USA

Email: pwright@me.berkeley.edu

e 210 Hearst Mining Building, University of California, Berkeley, CA USA 94720

Email: evans@berkeley.edu

${ }^{1}$ Present Address: The Pennsylvania State University, P.O. Box 30, State College, PA 16804

USA

${ }^{*}$ Corresponding Author 


\section{Keywords}

Electrodeposition; zinc anode secondary batteries; ionic liquids; morphology; in situ atomic force microscopy 


\section{Introduction}

The aim of this investigation was to understand the deposition behavior of zinc within an ionic liquid electrolyte system to further develop a better predictive structure-property relationship of metal deposition within ionic liquid systems. Zinc is an attractive material for rechargeable battery systems because it is energy dense (both gravimetrically and volumetrically), inexpensive, non-toxic and recyclable. Zinc based energy storage systems have exhibited high cyclability in excess of 1000 cycles for zinc-flow batteries and have exhibited high energy densities in primary zinc-air batteries $[1,2]$. Currently, however, zinc based rechargeable batteries have had limited commercial use for energy storage due to poor cyclability [3].

The zinc electrode is typically the limiting electrode in rechargeable battery systems due to its propensity for forming detrimental morphologies such as dendrites, nodules, and filaments [4, 5]. These detrimental morphologies can grow and penetrate through the electrolyte/separator region and short out the cell. Furthermore, these morphologies can break off from the electrode during dissolution effectively removing active material from the battery system. Therefore, it is essential to prevent the formation of these detrimental morphologies to ensure that the zinc electrode can undergo multiple charge/discharge cycles.

Ionic liquid based electrolytes exhibit unusual properties such as a wide electrochemical stability window, high thermal stability, and a low vapor pressure. These properties are attractive for rechargeable battery systems because they extend the operating range beyond those feasible with aqueous electrolytes [6]. Numerous studies have shown the ability to obtain a uniform metal deposition for coating applications within an ionic liquid electrolyte and, due to their importance, 
are the subject of regular reviews [7-10]. The majority of studies of zinc deposition (Table 1) have utilized the imidazolium or pyrrolidinium family of cations with chloride $(\mathrm{Cl})$, dicyanamide (DCA), trifluoromethylsulfonate (OTf), bis(trifluoromethanesulfonyl)imide (Tf2N) anions and either $\mathrm{ZnCl}_{2}, \mathrm{Zn}(\mathrm{TfO})_{2}$, or $\mathrm{Zn}(\mathrm{Tf} 2 \mathrm{~N})_{2}$ as the zinc source [11-18]. In addition, zinc has been deposited from choline chloride-based deep eutectic solvents [19-23] and ammonium based ionic liquids $[24,25]$. In general, the imidazolium family produces highly crystalline films composed of well-developed hexagonal facets $[11,12,14,26]$. The crystallites can range from thin to thick plates and under some conditions create textured films $[12,14]$ with the prism facet perpendicular to the surface. The pyrrolidinium family also creates crystalline films $[14,15,17$, 18] but tends to have finer grained crystallites that are more disordered and rounded. No textured morphologies have been described.

$$
<<\text { Table } 1>>
$$

Despite the fact that both the $\mathrm{BMIm}^{+}$cation and the $\mathrm{OTf}^{-}$anion have been independently investigated, none of the systems reported to date describe the compact, highly textured morphology reported here. In particular, although prism textured films have been reported, they are open porous structures where the plates are nucleated at high angles with respect to one another. These porous structures are also observed in zinc grown from sulfate solutions and appear to be a function of $\mathrm{pH}$. By contrast, this study describes dense domains with co-aligned prism-oriented hexagonal plates. 
There have been comparatively few studies that use in situ techniques to investigate zinc electrodeposition in ionic liquids. Underpotential deposition and Au-Zn alloying have been investigated by in situ scanning tunneling microscopy [13], in situ spectroscopy [13], and in situ X-ray diffraction (XRD) [11]. These studies describe the first few monolayers of electrodeposited zinc on gold within a Lewis acidic aluminum chloride-butyl methyl imidazolium chloride ionic liquid [13]. In addition, Smith et al. conducted an in situ investigation using atomic force microscopy (AFM) synchronized with a quartz crystal microbalance (QCM) to resolve both nucleation and growth of zinc on gold during electrodeposition with choline chloride based deep eutectic solvents [20]. These in situ investigations provide insights on the nucleation and growth of electrodeposited metal films that aid in the prediction of system behavior during high charge transfer deposition encountered within energy storage systems. No in situ studies to date, however, have described the evolution of morphology and roughness of zinc electrodeposition in BMIm OTf reported here.

In this work we use the height difference correlation function to quantify the surface morphology of polycrystalline zinc films electrodeposited from an ionic liquid over a range of overpotentials. The height difference correlation function is one in a family of related statistical functions that describe both the vertical and lateral fluctuations in surfaces. In surface physics, correlation functions (and the related interface width) have seen their greatest utility in describing self-affine morphologies [27-30] that develop during homoepitaxial growth for systems where there are no equilibrium or kinetic instabilities that cause mounding structures [31,32]. For self-affine surfaces the scaling exponents obtained from the correlation function or interface width can be used to describe universality classes that in principal connect morphologies with interfacial 
processes and with continuum descriptions of growth [33]. More recently these principals have been applied to heteroepitaxial and polycrystalline systems where mounded growth is typical even in the absence of growth instabilities (such as induced by step-edge barriers). In these cases, the surface is not expected to be self-affine at all scales because the mounds, or polycrystalline grains, tend to have a narrow size distribution. Instead, these films may have power law behavior over specific ranges and the exponents obtained can help describe the surface morphology but are not indicative of the traditional universality classes [34].

Despite this lack of connection to traditional universality classes, the height difference correlation function and the description of the vertical and lateral correlations in terms of power laws, are extremely useful for reducing a complex polycrystalline landscape into a few numbers that describe how a surface roughens spatially and in time. Furthermore, this reduction aids comparisons between systems.

In this paper, we report an in situ electrodeposition study of zinc within an imidazolium-based ionic liquid electrolyte consisting of zinc trifluoromethanesulfonate, $\mathrm{Zn}(\mathrm{OTf})_{2}$, dissolved within 1-butyl-3-methyl-imidazolium trifluoromethanesulfonate, BMIm OTf. This system was chosen because it has exhibited excellent cyclability as an electrolyte for printed battery applications [35]. In addition, imidazolium based ionic liquids have reasonable ionic conductivity and a wide electrochemical stability window. Depending on the anion, the ionic conductivity of BMIm based ionic liquids measures from 0.5 to $4 \mathrm{mS} \mathrm{cm}^{-1}$ and exhibits a stability window from 2.2 to over $4 \mathrm{~V}$ [6]. From the manufacturer, BMIm OTf used in this investigation had a reported ionic conductivity of $3.7 \mathrm{mS} \mathrm{cm}^{-1}$. 


\begin{abstract}
We used in situ electrochemical atomic force microscopy (AFM) to measure zinc surface morphology during electrodeposition within the ionic liquid electrolyte. Images were used to calculate the height difference correlation function as a function of deposition time. Surface evolution was analyzed in terms of the morphology, the local surface roughness, saturated surface roughness and lateral correlation length. Final morphologies were characterized by ex situ scanning electron microscopy and energy dispersive spectroscopy.
\end{abstract}

\title{
2. Experimental
}

\subsection{Ionic Liquid Electrolyte Preparation}

The ionic liquid preparation protocol closely follows the recommendations of Gnahm and Kolb [36]. Their procedure results in a more reproducible cyclic voltammogram with the ionic liquid which they attribute to the removal of impurities and residual water. The imidazolium based ionic liquid electrolyte with $0.34 \mathrm{~mol} \mathrm{~kg}^{-1}$ was prepared by dissolving the desired amount of zinc trifluoromethanesulfonate $\left(\mathrm{Zn}(\mathrm{OTf})_{2}\right.$, Sigma-Aldrich, 98\%) into 1-butyl-3-methyl-imidazolium trifluoromethanesulfonate (BMIm OTf, IoLiTec Ionic Liquids Technologies, $>99 \%$ ) at $80^{\circ} \mathrm{C}$. To help reduce impurities, molecular sieves (Fluka) of $3 \AA$ pore size were added to the electrolyte. The electrolyte was dried within a furnace at $100^{\circ} \mathrm{C}$ for 4 to 6 hours and stored within a desiccator under a vacuum of $25 \mathrm{~mm} \mathrm{Hg}$ for at least 24 hours prior to testing. The resulting electrolyte mixture was clear with a slight amber color.

\footnotetext{
We note that a series of electrochemistry and AFM experiments were performed using BMIm OTf from IoLiTec Ionic Liquids Technologies (99\%), EMD (high purity) and Sigma Aldrich
} 
(>98\%). All three ionic liquids had similar deposition efficiencies. However deposition in Sigma Aldrich, and to a lesser degree EMD, ionic liquids produced rounded zinc islands suggesting impurity interactions, whereas deposition in IoLiTec ionic liquid produced the expected hexagonal zinc morphology. For this reason, all results shown utilize BMIm OTf from IoLiTec Ionic Liquids Technologies.

\subsection{Cyclic Voltammetry Analysis of the Neat BMIm OTf}

The cyclic voltammetry of the neat BMIm OTf was conducted within a sealed glass flask. Dry argon gas flowed through the reservoir chamber throughout testing. The working and counter electrodes were $0.5 \mathrm{~mm}$ diameter platinum wires. The $\mathrm{Zn} / \mathrm{Zn}$ (II) reference electrode was assembled within a Teflon (PTFE) tube with a glass frit (Porous Vycor) junction. The reference electrode consisted of a $0.5 \mathrm{~mm}$ diameter zinc wire (Alfa Aesar, 99.995\%) immersed within a

$0.40 \mathrm{~mol} \mathrm{~L}^{-1} \mathrm{Zn}(\mathrm{OTf})_{2}$ dissolved within BMIm OTf. Cyclic voltammetry was conducted using a Bio-Logic SP-300 potentiostat/galvanostat and potentials were referenced to $\mathrm{Zn} / \mathrm{Zn}(\mathrm{II})$.

\subsection{Electrochemical AFM Cell Setup}

Zinc deposition was conducted on a platinum disk shaped substrate that was sputter deposited on a glass wafer shown in Figure 1. Figure 1 also shows the location of the AFM cantilever assembly in relation to the substrate as well as the probing areas on the substrate. The platinum electrode measured $1 \mathrm{~mm}$ in diameter with a thickness of $0.6 \mu \mathrm{m}$. The root mean square (RMS) surface roughness of the sputter deposited platinum substrate was $3.5+/-0.5 \mathrm{~nm}$ for a $4 \mu \mathrm{m} \times 4$ $\mu \mathrm{m}$ area as measured by AFM imaging. The electrical connection to the platinum substrate was obtained by a $0.1 \mathrm{~mm}$ wide $6 \mathrm{~mm}$ long platinum sputtered leg.

$<<$ Figure $1>>$ 
To remove contaminates, the platinum substrate was cleaned by submerging within $1 \mathrm{M} \mathrm{H}_{2} \mathrm{SO}_{4}$ for 5 minutes and washing with Millipore water. Subsequently, the substrate was plasma etched within a Harrick Plasma cleaner (Model PDC-32G) for 3 minutes.

Zinc deposition was conducted within a polyether ether ketone (PEEK) electrochemical AFM cell (Asylum Research). The counter and reference electrodes were zinc wire (Alfa Aesar, 99.995\%). To help maintain low water content within the electrolyte, molecular sieves (Fluka) with $3 \AA$ pores were added to the electrolyte reservoir chamber at roughly a 1 to 5 mass ratio and argon gas was percolated into the electrolyte through a port in the cell.

\subsection{Uncompensated Resistance}

Ionic liquid systems exhibit relatively low ionic conductivities on the order of two magnitudes lower than supported aqueous electrolyte systems, therefore, the uncompensated resistance for the system can be significant, particularly because limitations within the AFM cell geometry did not allow for placement of the reference wire closer than $10 \mathrm{~mm}$ to the platinum.

The uncompensated resistance, $R_{u}$, for the zinc deposition experiments was measured at 1700 $+/-200 \Omega$ by the current interrupt method [37]. For the CV analysis, the actual potential, $E_{\text {actual }}$, was determined from applied voltage, $E_{\text {applied }}$, and the measured $i R_{u}$ voltage drop following $E_{\text {actual }}=E_{\text {applied }}-i R_{u}$ where $i$ is the current. We did not account for the $i R_{u}$ voltage drop during growth. Instead we estimated the correction to the overpotential analytically. The $i R_{u}$ voltage drop for deposition at -400 and $-500 \mathrm{mV}$ versus the zinc wire varied from 4 $\mathrm{mV}$ to $35 \mathrm{mV}$. The $i R_{u}$ voltage drop for deposition at $-650 \mathrm{mV}$ varied from 47 to $125 \mathrm{mV}$. 


\subsection{Zinc Deposition}

Zinc was deposited potentiostatically using a Bio-Logic SP-300 potentiostat/galvanostat and ECLab ${ }^{\circledR}$ software (version 10.23). Electrodeposition was carried out at $25^{\circ} \mathrm{C}$. Prior to the AFM deposition analysis, the platinum substrate was initialized by potentiostatic reduction of zinc at $-500 \mathrm{mV}$ versus the $\mathrm{Zn}$ reference wire for a total charge passed of $52.3 \mathrm{mC} \mathrm{cm}$. The zinc deposit was then removed by potentiostatic oxidation at $+200 \mathrm{mV}$ versus the $\mathrm{Zn}$ reference wire. This initiation step eliminated uneven deposition that was often encountered with the first deposition pulse on the platinum substrate as seen visually from the optical microscope.

The in situ analyses of zinc deposition within the ionic liquid were conducted with pulses at a constant reducing potential (potentiostatic deposition) versus the zinc wire reference. The deposition behavior of zinc was analyzed in three experiments with the applied potentials of $-400,-500$, and $-650 \mathrm{mV}$ versus a zinc reference wire. These potentials are representative of the range between the onset of zinc deposition and the breakdown of the ionic liquid. The total charge passed per pulse was $104.6 \mathrm{mC} \mathrm{cm}^{-2}$ which corresponds to 200 zinc monolayers (ML) assuming $100 \%$ current efficiency. We calculated the relationship between the charge density and zinc ML using the average atomic spacing of $0.248 \mathrm{~nm}$, assuming randomly oriented grains.

\footnotetext{
As commonly done in the literature [12], we defined the deposition overpotential, $\eta$, as the difference between the applied potential, $E_{\text {applied }}$, and the observed crossover potential, $E_{C O}$. Accounting for the estimated uncompensated resistance, $i R_{u}, \eta$ was approximated by $\eta=$
} 
$E_{\text {applied }}-\bar{\imath} R_{u}-E_{C O}$ where $\bar{\imath}$ represents the average current during a pulse. Table 2 lists the electrodeposition parameters for each AFM test.

$<<$ Table 2>>

While imaging, the substrate voltage was held at approximately $10 \mathrm{mV}$ negative of $E_{C O}$. This was done because zinc (on the platinum substrate) continuously undergoes dissolution at OCP (perhaps due to pinholes or partial exposure of platinum at the disk edges). We confirmed by AFM that the zinc surface neither grew nor dissolved at the holding potential. The holding time was approximately 10 minutes per image. A total of 14 pulses were conducted for each reducing potential for a total charge passed of $1464.4 \mathrm{mC} \mathrm{cm}^{-2}$ or 2800 zinc monolayers assuming $100 \%$ current efficiency. For zinc deposition at $-400 \mathrm{mV}$ versus the zinc wire, the first deposition pulse was conducted at $-500 \mathrm{mV}$ to ensure nucleation.

Each of the deposition pulses exhibited a peak current after which the current steadily decreased approaching steady state (Figure 2). The peak shape is attributed to an increase in active area associated with nucleation followed by a decrease in current associated with diffusion-limited growth. The consistency of magnitude and shape throughout the course of an experiment (14 pulses) indicated that the electrochemical environment (zinc concentration, water concentration etc.) was not changing significantly. Deposition at $325 \mathrm{mV}$ overpotential exhibited a similar current transient behavior, however, the peak began to flatten after the second pulse.

$<<$ Figure $2>>$ 


\subsection{AFM Measurement}

In situ atomic force microscopy (AFM) of the zinc deposition was conducted using an Asylum MFP3D instrument. AFM imaging was performed using a silicon nitride tip on a silicon nitride cantilever (Olympus TR800PSA) in contact mode. The AFM tip assembly had a $200 \mu \mathrm{m}$ and 100 $\mu \mathrm{m}$ cantilever that were used to measure thickness and surface roughness, respectively. The short lever was used to quantify the zinc surface morphology with small scan areas $(4 \mu \mathrm{m} \times 4 \mu \mathrm{m})$ where care was taken to preserve the sharpness of the tip by scanning with minimum force (Figure 1). At selected intervals, the long lever was used to scan a $90 \mu \mathrm{m} \times 90 \mu \mathrm{m}$ area across the edge of the platinum electrode (Figure 3). The total electrode thickness was measured using the glass as a height reference and subtracting the original platinum substrate thickness from the average total thickness measured after zinc deposition.

The lateral resolution expected in contact mode [38] with this type of tip and instrument is $d=\sqrt{8 R \Delta z}$ where $\mathrm{R}$ is the manufacturer tip radius, $20 \mathrm{~nm}$, and $\Delta z$ is the vertical resolution of the AFM, $\sim 0.1 \mathrm{~nm}$, resulting in a lateral resolution of $d \sim 4 \mathrm{~nm}$. However, for $4 \mu \mathrm{m}$ images captured with 512 pixels per line, each pixel corresponds to $\sim 8 \mathrm{~nm}$, which becomes the limiting resolution. The effective tip radius can change over the course of an experiment due to blunting of the tip or attachment of debris to the tip, but it would be unlikely that these effects would shift the resolution to a value larger than one pixel without noticeable imaging artifacts. As an additional test, we compared AFM and SEM measurements of platelet widths of the final surfaces. These were found to agree within the standard deviation of the measurement. 
During potentiostatic electrodeposition the AFM assembly was moved off the platinum substrate to ensure that it was not electrically shielding the substrate or creating an occluded volume that limited diffusion. The assembly could be returned to same location within $2 \mu \mathrm{m}$, allowing relocation of the same features.

\author{
$<<$ Figure 3 $>>$
}

\title{
2.7. Ex-Situ Analysis of the Zinc Deposition Morphology
}

The zinc deposits obtained after deposition at 325 and $445 \mathrm{mV}$ overpotentials were removed for ex situ SEM analysis. The ionic liquid electrolyte was washed from the sample with ethanol and Millipore water (18 ohm-cm). Electron microscopy was conducted on a JEOL JSM-7401F FESEM scanning electron microscope. Grain size analysis was conducted on the SEM images by intercept counting using a grid of concentric circles as outlined by ASTM E112 [39]. The mean linear intercept, $\bar{l}$, is the average distance between grain intersections with the concentric circle grid. The mean spatial radius, $\bar{R}$, was calculated from the mean linear intercept based on the assumption that the zinc grains follow a tetrakaidecahedron shape model using the relation, $\bar{R}=0.7855 \bar{l}[39]$. The reported grain size was averaged from five separate SEM images that were obtained at various locations on the substrate surface. 


\section{Results and Discussion}

\subsection{Electrochemical Behavior of the Pt Electrode within the IL Electrolyte}

Cyclic voltammetry (CV) demonstrates that neat BMIm OTf (inset within Figure 4) has an electrochemical stability window of approximately $2.6 \mathrm{~V}$ with limits at -0.9 and $1.7 \mathrm{~V}$ versus $\mathrm{Zn} / \mathrm{Zn}(\mathrm{II})$. No peaks were observed that would point to the presence of water within the neat BMIm OTf.

$<<$ Figure $4>>$

CV's were also obtained from the platinum substrate within the $0.34 \mathrm{~mol} \mathrm{~kg}^{-1} \mathrm{Zn}(\mathrm{OTf})_{2} / \mathrm{BMIm}$ OTf electrolyte within the electrochemical AFM cell. Figure 4 shows the CV of the platinum substrate and a repeat CV on the same platinum substrate after zinc deposition and oxidation. The cathodic current corresponds to the reduction of $\mathrm{Zn}$ (II) on the platinum electrode and the anodic current corresponds to the dissolution of zinc forming $\mathrm{Zn}$ (II). The initial electrodeposition of zinc on the platinum electrode initiated at $-480 \mathrm{mV}$ versus the $\mathrm{Zn}$ reference wire. Using the crossover potential as a reference, the nucleation overpotential (NOP) is $270 \mathrm{mV}$. The high NOP is consistent with literature reports of zinc nucleation in the presence of $\mathrm{BMIm}^{+}$additives [12] where the authors suggest that $\mathrm{BMIm}^{+}$adsorbs to and blocks the working electrode causing a shift in nucleation overpotential. Repeating the $\mathrm{CV}$ on the same substrate after zinc deposition and oxidation resulted in a lower NOP of $190 \mathrm{mV}$, which can be attributed to a change in BMIm ${ }^{+}$ adsorption, surface alloying, or remnant zinc on the surface that aids subsequent nucleation. The cathodic current exhibited diffusion limited behavior with a peak current density at $-680 \mathrm{mV}$ versus the $\mathrm{Zn}$ reference wire for the initial $\mathrm{CV}$ and $-620 \mathrm{mV}$ for the repeat $\mathrm{CV}$. The large 
potential difference between the cathodic and anodic peaks of $0.9 \mathrm{~V}$ indicates that this system is irreversible. Furthermore, the integrated electric charge transfer during oxidation was approximately $90 \%$ of the charge transfer during the anodic scan. The smaller charge transfer during oxidation suggests that either the zinc reduced during the cathodic scan was not oxidized completely during the anodic scan or that there was a parasitic reaction occurring during the cathodic scan. The anodic to cathodic crossover for the initial and repeat CV was at $-212 \mathrm{mV}$ and $-181 \mathrm{mV}$ versus the zinc reference wire respectively. For an ideal $\mathrm{Zn} / \mathrm{Zn}(\mathrm{II})$ reference, the crossover would approach $0 \mathrm{~V}$. The low potential of the observed crossover was attributed to differences in surface chemistry between the zinc wire and the freshly deposited zinc.

From the $\mathrm{CV}$ analysis, the window of zinc deposition on the working electrode within the $\mathrm{Zn}(\mathrm{OTf})_{2} / \mathrm{BMIm}$ OTf electrolyte was from approximately $-400 \mathrm{mV}$ to $-750 \mathrm{mV}$ versus a $\mathrm{Zn}$ reference wire for the AFM electrochemical cell.

\subsection{Zinc Deposition Thickness}

Deposition efficiency was measured in two ways: (1) by comparing the anodic and cathodic charge during CVs as described above, and (2) by measuring the film thickness as a function of charge passed (Figure 5). An ideal electrodeposition rate, assuming 100\% electrodeposition efficiency, was calculated to be $0.248 \mathrm{~nm}$ per $\mathrm{Zn}$ monolayer; the measured zinc deposition rate was $0.23 \mathrm{~nm}$ (best line fit, Figure 5) or approximately $90 \%$ of the ideal rate. This value was close to the measured deposition efficiency from the $\mathrm{CV}$ analysis, which was also approximately $90 \%$. These two measurements indicate that the zinc deposits as a compact layer with minimal porosity. 


\section{$<<$ Figure $5>>$}

\subsection{Zinc Deposition Morphology}

Figure 6 shows a typical deposition sequence. In the initial stages of growth, hexagonal zinc islands form on the platinum substrate. The basal facets are slower growing than the prism facets (as reflected by the anisotropic platelet morphology). Initially platelets are randomly oriented with respect to the interface (Figures 6a-6d). Over time the faster growing prismatic facets outcompete the basal facets, creating a textured surface. The crystals are oriented such that the fastest growing direction, which is the intersection between two prism facets, is perpendicular to the interface (Figure 7a). However instead of a completely random distribution of prism-oriented crystallites, the surface forms domains of co-aligned platelets (Figure 7b). These domains of coaligned crystals increase in size, scaling roughly as the platelet diameter (Figures 6e-6j). As a result the surface has two apparent length scales: the platelet thickness, which is approximately constant over time at $\sim 35 \mathrm{~nm}$ and the domain size, which is roughly the platelet diameter, which grows to over $200 \mathrm{~nm}$.

$<<$ Figure 6>>

$<<$ Figure $7>>$

Figure 8 shows SEM micrographs of the final deposition morphology for two of the overpotentials, $325 \mathrm{mV}$ and $445 \mathrm{mV}$. Large-scale SEM imaging verified that the morphology is representative of the entire surface and smaller area scans were in good agreement with the AFM 
results confirming a compact and dense deposit. The zinc deposition morphology exhibited orientational ordering with zinc grains composed of stacked parallel hexagonal plates. The morphology differs from the boulder morphology or layer-like morphology that has been observed with zinc deposition from aqueous alkaline battery electrolytes. First, the platelets are thin, unlike the boulder morphology; second they are prism-oriented unlike layer-like growth; and third the crystal dimensions are one to two orders of magnitude smaller in the present investigation [40]. Energy-dispersive X-ray spectroscopy (data not shown) confirmed that the deposition was zinc.

$$
<<\text { Figure } 8>>
$$

The average grain size was measured from the SEM micrographs and is listed in Table 3. The mean spatial radius of the zinc grains was similar for both deposition at 325 and $445 \mathrm{mV}$ overpotentials. Deposition at $325 \mathrm{mV}$ overpotential exhibited a slightly higher mean spatial radius of $200 \mathrm{~nm}$ than the deposition at $445 \mathrm{mV}$ overpotential, which was measured at $190 \mathrm{~nm}$. Finally, the small standard deviation, $\mathrm{SD}$, of the grain size data points to a consistent grain size across the disk electrode surface.

$<<$ Table 3>>

\subsection{Height Difference Correlation Function}

The height-difference correlation function is a graphical representation of the roughness and spatial correlations across a surface. It provides statistical metrics for the degree of coupling 
between vertical roughening and lateral smoothing. One of the distinct advantages of an in situ approach is an ability to measure the temporal evolution of these statistical metrics.

The height difference correlation function, $g(x)$, was calculated from the AFM images after each deposition pulse using

$$
g(x)=\left\langle\left[h\left(x+x_{0}, y_{0}\right)-h\left(x_{0}, y_{0}\right)\right]^{2}\right\rangle
$$

where $h\left(x_{0}, y_{0}\right)$ represents the surface height at point $x_{0}, y_{0}$ and \langle\rangle indicates an average over all points in the image $\left(x_{0}, y_{0}\right)$, and $x$ is the fast scanning direction. Such plots (Figure 9) typically show that roughness increases with power law behavior below a characteristic correlation length, $\xi$, and saturates, remaining constant, at scales above the correlation length. Our films are composed of faceted crystals with characteristic platelet and domain sizes and are therefore not fractal. Nevertheless, the three characteristic values; the roughness, Hurst exponent and correlation length; can be fitted with a Gaussian form [41] such that

$$
g(x)=2 w_{s a t}^{2}\left\{1-\exp \left[-\left(\frac{x}{\xi}\right)^{2 \alpha}\right]\right\}
$$

where the interface width, $w_{s a t}$, is the root mean square (RMS) value of the surface height deviation, $\xi$ is the lateral correlation length, and $\alpha$ is is the Hurst exponent. The data and fits (solid line) for the three deposition conditions are shown in Figure 9 for selected amounts of total charged passed. Fit values are summarized in Table 4. Fits are not sensitive to the Gaussian form of the correlation function; similar values are found assuming straight line fits above and below the knee and choosing the correlation length to be the intersection.

$$
<<\text { Table } 4>>
$$

$<<$ Figure 9>> 


\subsubsection{Hurst Exponent}

The Hurst exponent (also termed static scaling exponent), $\alpha$, was found to be $0.82+/-0.03$ for the sputter-deposited platinum substrate. After zinc deposition, the exponent increased closer to one and remained relatively constant with continued deposition. The exponent averaged $0.89 \pm$ $0.03,0.88 \pm 0.04$, and $0.89 \pm 0.05$ for the three overpotentials of 245,325 , and $445 \mathrm{mV}$, respectively. The Hurst exponent indicates the scaling between vertical and lateral features and provides a measure of the smoothness of the local surface in the range below the correlation length, $\xi$. A scaling exponent approaching zero indicates ballistic deposition with no smoothing mechanisms and a scaling exponent approaching one is consistent with lateral smoothing, for example due to diffusion [41]. Our Hurst exponent, $\alpha \sim 0.9$, suggests that the zinc deposition exhibits a locally smooth surface that is consistent with solution or surface diffusion and faceting. In addition, the Hurst exponent remained relatively constant throughout the deposition.

\subsubsection{Local versus Saturated Interface Width and the Growth Exponent}

The RMS value of the height difference for both the local (arbitrarily chosen at $x=40 \mathrm{~nm}$ ) and the saturated surface $(x>\xi)$ is shown in Figure 10 for each of the deposition conditions. The local surface RMS roughness increases for the first few hundred Zn monolayers. This signature of the HHCF is often termed anomalous scaling but for our case of heteroepitaxial growth it is more useful to think of this behavior as transitory while the morphology changes from platinum islands to zinc platelets. After $400 \mathrm{Zn}$ monolayers, the local roughness remained constant or slightly decreased for all overpotential values, another indication that this should not be construed as anomalous scaling. Similar behavior has been observed in copper electrodeposition where a constant local roughness was attributed to the development of a dominant crystalline 
texture [42]. This is in agreement with the AFM images, which show the surface evolving from random to prism dominated over this thickness range. Although we note that texture evolution is a progression that continues as the film thickens.

\title{
$<<$ Figure $10>>$
}

\begin{abstract}
In contrast to the local roughness, the saturated roughness for deposition at $245 \mathrm{mV}$ and $445 \mathrm{mV}$ overpotentials continued to increase and the zinc surface became rougher over time. A constant local surface roughness along with an increasing saturated roughness is consistent with normal scaling behavior [43]. Interestingly, the saturated surface roughness for the deposition at $325 \mathrm{mV}$ overpotential, did not increase above $1200 \mathrm{Zn}$ monolayers of charge passed. We note that both the electrochemical current-voltage data and independent large-scale AFM measurements of the film thickness confirmed that the film continued to grow. We have a sparse number of trials thus the robustness of these results have not been thoroughly tested but we have also observed saturation of the roughness using $2 \mathrm{~mA} \mathrm{~cm}^{-2}$ pulses in EMD ionic liquid out to $1600 \mathrm{ML}$ [44]. A constant roughness is not typically encountered with electrodeposition in the absence of additives [43] nor is it expected from texture evolution models [45].
\end{abstract}
In the interest of connecting with other studies that describe surface evolution in terms of scaling theories, we have extracted the growth exponent for the two overpotentials where roughness continued to increase with deposition time. We omit the first measurement at $200 \mathrm{ML}$ because these reflect the transition from a platinum substrate. The RMS roughness of the saturated surface, $w_{\text {sat }}$, scales exponentially with the amount of charge passed, $Q$, such that $w_{\text {sat }} \sim Q^{\beta}$


where $\beta$ is termed the growth exponent $[29,33]$. The best power law fits (Figure 11) give the kinetic exponent to be 0.46 and 0.42 for overpotentials of 245 and $445 \mathrm{mV}$ respectively.

Although, for thicknesses above the transitory region, these HHCF have a form consistent with normal scaling, we will show that the surfaces are inconsistent with normal scaling relations. For an overpotential of $325 \mathrm{mV}$, the roughness did not increase with deposition time beyond $\sim 400$ MLs making $\beta$ ill-defined (or $\beta=0$ above 400 MLs).

$<<$ Figure 11 $>>$

\subsubsection{Lateral Correlation Length and the Dynamic Exponent}

The lateral correlation length, $\xi$, also scales with the amount of charge passed following $\xi \sim Q^{1 / z}$ where the dynamics exponent, $z=\alpha / \beta$ for systems that comply with the FamilyVicsek dynamic scaling ansatz $[28,29,33]$. The lateral correlation length, $\xi$, for each of the deposition conditions versus the amount of charge passed is shown in Figure 12. The growth of the lateral correlation length for each of the deposition conditions was approximately independent of overpotential with exponents of $0.63,0.64$, and 0.62 for depositions at 245,325 $\mathrm{mV}$ and $445 \mathrm{mV}$ overpotentials, respectively. Again, we omit the first measurement at $200 \mathrm{ML}$ because these reflect the transition from a platinum substrate rather than simply the evolution of zinc islands. Thus the dynamic exponent is $z \sim 1.6$ for all overpotentials measured.

$<<$ Figure $12>>$ 
For a polycrystalline surface it seems reasonable to expect a higher degree of height correlation within a domain as opposed to between grains. Thus we expect the lateral correlation length, $\xi$, to reflect the domain structure as has been shown for other polycrystalline surfaces [46]. After $2800 \mathrm{Zn}$ monolayers of charge has passed, the lateral correlation length as measured from the height-difference correlation function was $190 \mathrm{~nm}$ and $160 \mathrm{~nm}$ for deposition at 325 and $445 \mathrm{mV}$ overpotentials respectively. These values are close to the mean spatial radius of the zinc grains as measured from the SEM analysis $(200 \pm 6 \mathrm{~nm}$ and $190 \pm 17 \mathrm{~nm}$ for deposition at 325 and 445 $\mathrm{mV}$ overpotentials respectively). Therefore, we believe that the dynamic exponent corresponds to lateral coarsening of the domains.

\subsubsection{Surface Evolution during Electrodeposition of Zinc}

In this investigation, we used the height difference correlation function to describe the surface evolution of zinc during electrodeposition on a Pt substrate within a BMIm OTf ionic liquid electrolyte. The scaling factors describe how the surface roughens perpendicular (roughness) and parallel (lateral correlation) to the interface. There have been several reports describing electrodeposited films in terms of scaling parameters [47-50]. Most of these focus on the relationship between scaling above and below the correlation length, (i.e. local versus saturated values of $\beta[50])$.

In our case, the HHCF was used to argue that the growth should be considered in two stages. The first stage was transitory as zinc nucleated on platinum and changed to a zinc morphology. During this stage the local roughness changed rapidly. The second stage was representative of polycrystalline growth of zinc on a zinc substrate. In the second stage, the local roughness varied slowly or was constant corresponding to $\beta_{\text {local }} \sim 0$. The fact that $\beta_{\text {local }}$ is not single valued is an 
indication that neither anomalous nor normal scaling holds over the full growth cycle. As a further test to determine whether scaling relations describe our system, we can assess $\alpha$ and $\beta$ above $400 \mathrm{ML}$ (where $\beta_{\text {local }} \sim 0$ ) to determine whether the morphological evolution is geometrically consistent with the scaling relation $w(L, t) \propto L^{\alpha} f\left(t / L^{Z}\right)$. Surfaces that obey this relation have the property that $z=\alpha / \beta$. By tracking the same surface in time we have independently extracted traditional scaling exponents $\alpha(\sim 0.9), \beta$ (zero or $\sim 0.46)$ and $z(\sim 1.6)$ thus demonstrating that $z \neq \alpha / \beta$. This indicates that our surfaces do not obey the scaling relation. Although many authors describe their surfaces as obeying normal scaling relations, there have been few reports $[51,52]$ that directly test consistency with the scaling law, $z=\alpha / \beta$ [27].

This is not an unexpected result for a polycrystalline, faceted interface. In such a system one might expect discontinuities at grain boundaries to cause diffusion bias that result in instabilities [31] and size selection. And in fact the zinc surface has domains within a fairly narrow size distribution rather than having features at all length scales. For these reasons we believe the temporal evolution reflects coarsening grain growth and texture evolution [34] rather than the coalescence of epitaxial islands where fractal surfaces with universal scaling laws have been described and tested [27, 53].

Simple models of texture evolution predict the roughness and grain size of randomly nucleated face-centered and body-centered cubic interfaces to grow as $\mathrm{t}^{2 / 5}[45,54,55]$. The zinc interfaces that continue to roughen in time (i.e. those grown at overpotentials of 225 and $445 \mathrm{mV}$ ) are close to these predictions with measured vertical roughness growing as $\mathrm{t}^{0.45}$ and domains growing as $\mathrm{t}^{0.6}$. However, these models do not account for differences in geometry for a hexagonal close 
packed system as required for zinc nor do they account for continued nucleation, which is likely important in our system. More pointedly these models do not predict a slowing or cessation of vertical roughening with deposition time as found for certain overpotentials $(325 \mathrm{mV})$ in this study. Thus we know of no surface evolution models that consistently describe the zinc surface but believe that understanding the mechanisms behind roughness cessation is a fruitful area for study.

\section{Conclusions}

Pulsed potentiostatic electrodeposition of zinc within the BMIm OTf electrolyte resulted in a dense and compact deposit organized into domains of oriented zinc platelets that ranged in size from 190 to $200 \mathrm{~nm}$ for the potentials investigated. The surface evolution was measured using the height difference correlation function. This was used to extract the temporal evolution of the vertical roughness and the lateral correlations. Although a temporal scaling factor for the surface roughness was obtained for deposition at 245 and $445 \mathrm{mV}$ overpotentials, deposition at $325 \mathrm{mV}$ overpotential did not increase with power law behavior. Instead, this surface appeared to reach a state where the surface roughness did not increase with film thickness. In contrast, the scaling behavior of the lateral correlation length grew with power law behavior reflecting the consolidations of grains of oriented platelets. This finding is of particular interest for energy storage applications because a small and constant surface roughness reduces the probability of forming surface instabilities that induce detrimental features such as dendrites. We hypothesize that the ability of the zinc surface to reach a constant surface roughness is related to the texture evolution and the formation of domains of co-aligned platelets. 


\section{Acknowledgements}

This work was supported by the Public Interest Energy Research Program of the California

Energy Commission and the Lawrence Livermore National Laboratory Directed Research and

Development Program, 12-LW-030. JSK gratefully acknowledges support from the Lawrence

Scholars Program at Lawrence Livermore National Laboratory. Portions of this work were

performed under the auspices of the U.S. Department of Energy by Lawrence Livermore

National Laboratory under Contract DE-AC52-07NA27344.

\section{References}

[1] Y. Ito, M. Nyce, R. Plivelich, M. Klein, D. Steingart, S. Banerjee, Zinc morphology in zinc-nickel flow assisted batteries and impact on performance, J Power Sources, 196 (2011) 2340-2345.

[2] F.R. McLarnon, E.J. Cairns, The secondary alkaline zinc electrode, J Electrochem Soc, 138 (1991) 645-664.

[3] F. Beck, P. Ruetschi, Rechargeable batteries with aqueous electrolytes, Electrochim Acta, 45 (2000) 2467-2482.

[4] R.V. Moshtev, P. Zlatilova, Kinetics of growth of zinc dendrite precursors in zincate solutions, J Appl Electrochem, 8 (1978) 213-222.

[5] Y. Oren, U. Landau, Growth of zinc dendrites in acidic zinc chloride solutions, Electrochim Acta, 27 (1982) 739-748.

[6] M. Galinski, A. Lewandowski, I. Stepniak, Ionic liquids as electrolytes, Electrochim Acta, 51 (2006) 5567-5580.

[7] W. Simka, D. Puszczyk, G. Nawrat, Electrodeposition of metals from non-aqueous solutions, Electrochim Acta, 54 (2009) 5307-5319.

[8] A.P. Abbott, K.J. McKenzie, Application of ionic liquids to the electrodeposition of metals, Phys Chem Chem Phys, 8 (2006) 4265-4279.

[9] F. Endres, F. Endres, D. MacFarlane, A. Abbott, Electrodeposition from Ionic Liquids, Wiley 2008.

[10] A.P. Abbott, G. Frisch, K.S. Ryder, Electroplating Using Ionic Liquids, Annu Rev Mater Res, 43

(2013) 335-358.

[11] D. Borissov, A. Pareek, F.U. Renner, M. Rohwerder, Electrodeposition of Zn and Au-Zn alloys at low temperature in an ionic liquid, Phys Chem Chem Phys, 12 (2010) 2059-2062.

[12] Q.B. Zhang, Y.X. Hua, Influence of [BMIM]HSO4 on electrodeposition and corrosion behavior of Zn coatings from acidic sulfate bath, Surf Interface Anal, 44 (2012) 1254-1260.

[13] J. Dogel, W. Freyland, Layer-by-layer growth of zinc during electrodeposition on $\mathrm{Au}(111)$ from a room temperature molten salt, Phys Chem Chem Phys, 5 (2003) 2484-2487.

[14] Z. Liu, S.Z. El Abedin, F. Endres, Electrodeposition of zinc films from ionic liquids and ionic liquid/water mixtures, Electrochim Acta, 89 (2013) 635-643.

[15] M. Xu, D.G. Ivey, W. Qu, Z. Xie, E. Dy, X.Z. Yuan, Zn/Zn(II) Redox Kinetics and Zn Deposit Morphology in Water Added Ionic Liquids with Bis(trifluoromethanesulfonyl)imide Anions, J Electrochem Soc, 161 (2013) A128-A136. 
[16] T.J. Simons, A.A.J. Torriero, P.C. Howlett, D.R. MacFarlane, M. Forsyth, High current density, efficient cycling of $\mathrm{Zn} 2+$ in 1-ethyl-3-methylimidazolium dicyanamide ionic liquid: The effect of Zn2+ salt and water concentration, Electrochem Commun, 18 (2012) 119-122.

[17] M.J. Deng, P.C. Lin, J.K. Chang, J.M. Chen, K.T. Lu, Electrochemistry of Zn(II)/Zn on Mg alloy from the N-butyl-N-methylpyrrolidinium dicyanamide ionic liquid, Electrochim Acta, 56 (2011) 60716077.

[18] C. Fournier, F. Favier, Zn, Ti and Si nanowires by electrodeposition in ionic liquid, Electrochem Commun, 13 (2011) 1252-1255.

[19] A.P. Abbott, J.C. Barron, K.S. Ryder, Electrolytic deposition of Zn coatings from ionic liquids based on choline chloride, Transactions of the Institute of Metal Finishing, 87 (2009) 201-207.

[20] E.L. Smith, J.C. Barron, A.P. Abbott, K.S. Ryder, Time resolved in situ liquid atomic force microscopy and simultaneous acoustic impedance electrochemical quartz crystal microbalance measurements: A study of Zn deposition, Anal Chem, 81 (2009) 8466-8471.

[21] A. Gomes, A.S. Viana, M.I.D.S. Pereira, Potentiostatic and AFM morphological studies of Zn electrodeposition in the presence of surfactants, J Electrochem Soc, 154 (2007) D452-D461. [22] L. Vieira, A.H. Whitehead, B. Gollas, Mechanistic Studies of Zinc Electrodeposition from Deep Eutectic Electrolytes, J Electrochem Soc, 161 (2013) D7-D13.

[23] A.P. Abbott, G. Capper, K.J. McKenzie, K.S. Ryder, Electrodeposition of zinc-tin alloys from deep eutectic solvents based on choline chloride, J Electroanal Chem, 599 (2007) 288-294.

[24] P.Y. Chen, C.L. Hussey, The electrodeposition of Mn and Zn-Mn alloys from the room-temperature tri-1-butylmethylammonium bis((trifluoromethane)sulfonyl)imide ionic liquid, Electrochim Acta, 52 (2007) 1857-1864.

[25] P. D'Angelo, A. Zitolo, F. Ceccacci, R. Caminiti, G. Aquilanti, Structural characterization of zinc(II) chloride in aqueous solution and in the protic ionic liquid ethyl ammonium nitrate by $\mathrm{X}$-ray absorption spectroscopy, J Chem Phys, 135 (2011).

[26] M. Xu, D.G. Ivey, Z. Xie, W. Qu, Electrochemical behavior of Zn/Zn(II) couples in aprotic ionic liquids based on pyrrolidinium and imidazolium cations and bis(trifluoromethanesulfonyl)imide and dicyanamide anions, Electrochim Acta, 89 (2013) 756-762.

[27] F. Family, T. Vicsek, Scaling of the Active Zone in the Eden Process on Percolation Networks and the Ballistic Deposition Model, J Phys a-Math Gen, 18 (1985) L75-L81.

[28] P. Meakin, The Growth of Rough Surfaces and Interfaces, Phys Rep, 235 (1993) 189-289.

[29] A.L. Barabasi, H.E. Stanley, Fractal Concepts in Surface Growth, Cambridge Univ Press 1995.

[30] J. Villain, Continuum Models of Crystal-Growth from Atomic-Beams with and without Desorption, J Phys I, 1 (1991) 19-42.

[31] C. Orme, B.G. Orr, Surface evolution during MBE growth, Surf Rev Lett, 4 (1997) 71-105.

[32] J.A. Stroscio, D.T. Pierce, M.D. Stiles, A. Zangwill, L.M. Sander, Coarsening of Unstable SurfaceFeatures during Fe(001) Homoepitaxy, Phys Rev Lett, 75 (1995) 4246-4249.

[33] W.M. Tong, R.S. Williams, Kinetics of surface growth - phenomenology, scaling, and mechanisms of smoothening and roughening, Annu Rev Phys Chem, 45 (1994) 401-438.

[34] L.H. Liu, W. Schwarzacher, Slope analysis and scaling analysis of electrodeposited thin films, Electrochem Commun, 29 (2013) 52-54.

[35] C.C. Ho, J.W. Evans, P.K. Wright, Direct write dispenser printing of a zinc microbattery with an ionic liquid gel electrolyte, J Micromech Microeng, 20 (2010).

[36] M. Gnahm, D.M. Kolb, The purification of an ionic liquid, J Electroanal Chem, 651 (2011) 250-252.

[37] A.J. Bard, L.R. Faulkner, Electrochemical Methods: Fundamentals and Applications, Wiley 2000.

[38] Y. Gan, Atomic and subnanometer resolution in ambient conditions by atomic force microscopy, Surf Sci Rep, 64 (2009) 99-121.

[39] A. International, Standard Test Methods for Determining Average Grain Size, ASTM International, West Conshohocken, PA, 2013.

[40] R.Y. Wang, D.W. Kirk, G.X. Zhang, Effects of deposition conditions on the morphology of zinc deposits from alkaline zincate solutions, J Electrochem Soc, 153 (2006) C357-C364. 
[41] S.K. Sinha, E.B. Sirota, S. Garoff, H.B. Stanley, X-ray and neutron scattering from rough surfaces, Physical Review B, 38 (1988) 2297-2311.

[42] M.C. Lafouresse, P.J. Heard, W. Schwarzacher, Anomalous scaling for thick electrodeposited films, Phys Rev Lett, 98 (2007) 236101.

[43] L. Guo, G. Oskam, A. Radisic, P.M. Hoffmann, P.C. Searson, Island growth in electrodeposition, J Phys D Appl Phys, 44 (2011).

[44] J. Keist, C. Orme, F. Ross, D. Steingart, P. Wright, J. Evans, Coupling in-situ techniques to analyze zinc deposition and dissolution for energy storage applications, MRS Fall Meeting, Materials Research Society, Boston, MA, 2012.

[45] P. Smereka, X.Q. Li, G. Russo, D.J. Srolovitz, Simulation of faceted film growth in three dimensions: microstructure, morphology and texture, Acta Materialia, 53 (2005) 1191-1204. [46] C. Schug, S. Schempp, P. Lamparter, S. Steeb, Surface roughness of sputter-deposited gold films: a combined X-ray technique and AFM study, Surf Interface Anal, 27 (1999) 670-677.

[47] N.D. Nikolic, Z. Rakocevic, D.R. Djurovic, K.I. Popov, Nanostructural analysis of mirror-bright zinc coatings, Russ J Electrochem+, 42 (2006) 1121-1126.

[48] A. Iwamoto, T. Yoshinobu, H. Iwasaki, Stable growth and kinetic roughening in electrochemical deposition, Phys Rev Lett, 72 (1994) 4025-4028.

[49] A. Osafo-Acquaah, Y. Shapir, J. Jorne, Transition in surface growth from self-affine to mounds during copper electrodeposition, J Electrochem Soc, 153 (2006) C535-C539.

[50] S. Huo, W. Schwarzacher, Anomalous scaling of the surface width during Cu electrodeposition, Phys Rev Lett, 86 (2001) 256-259.

[51] P. Cordoba-Torres, T.J. Mesquita, I.N. Bastos, R.P. Nogueira, Complex dynamics during metal dissolution: from intrinsic to faceted anomalous scaling, Phys Rev Lett, 102 (2009) 055504.

[52] F.S. Nascimento, S.C. Ferreira, S.O. Ferreira, Faceted anomalous scaling in the epitaxial growth of semiconductor films, Epl-Europhys Lett, 94 (2011) 68002.

[53] M. Kardar, G. Parisi, Y.C. Zhang, Dynamic Scaling of Growing Interfaces, Phys Rev Lett, 56 (1986) 889-892.

[54] A. Kolmogorov, Geometric Selection, Dok Acad Nauk USSR, 65 (1949) 681-684.

[55] A. Van der Drift, Evolutionary Selection a Principle Governing Growth Orientation in VapourDeposited Layers, Philips Res Rep, 22 (1967) 267-288. 


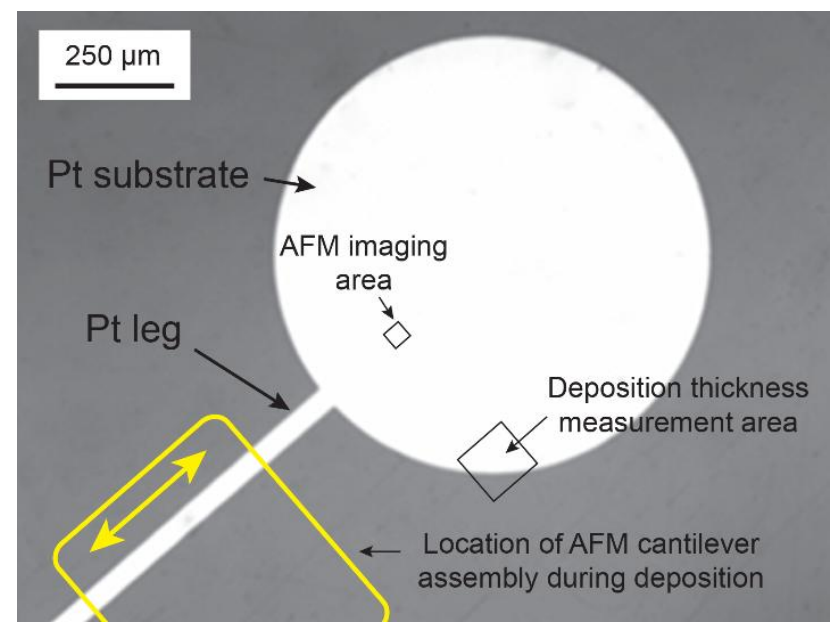

Figure 1

Optical micrograph of the Pt disk electrode and Pt leg. AFM probing areas are highlighted. During deposition, the AFM cantilever assembly was moved away from the electrode to the location highlighted schematically. 

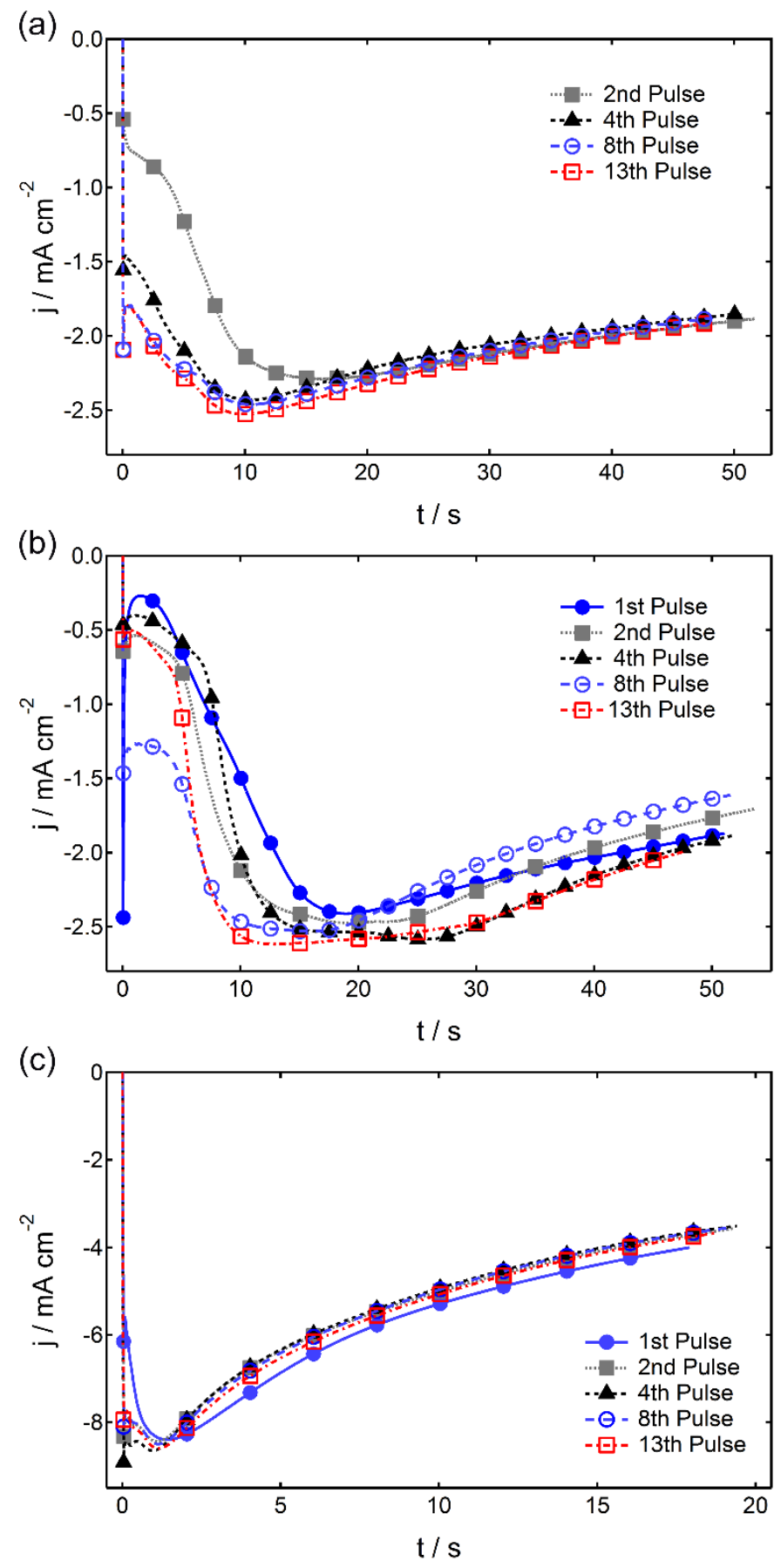

Figure 2

Selected chronoamperograms of zinc deposition pulses in $0.34 \mathrm{~mol} \mathrm{~kg}^{-1} \mathrm{Zn}(\mathrm{OTf})_{2} / \mathrm{BMIm}$ OTf at (a) $245 \mathrm{mV}$, (b) $325 \mathrm{mV}$, and (c) $445 \mathrm{mV}$ overpotential. The total charge passed for each deposition pulse was $104.6 \mathrm{mC} \mathrm{cm}^{-2}$ (200 $\mathrm{Zn}$ monolayers). 


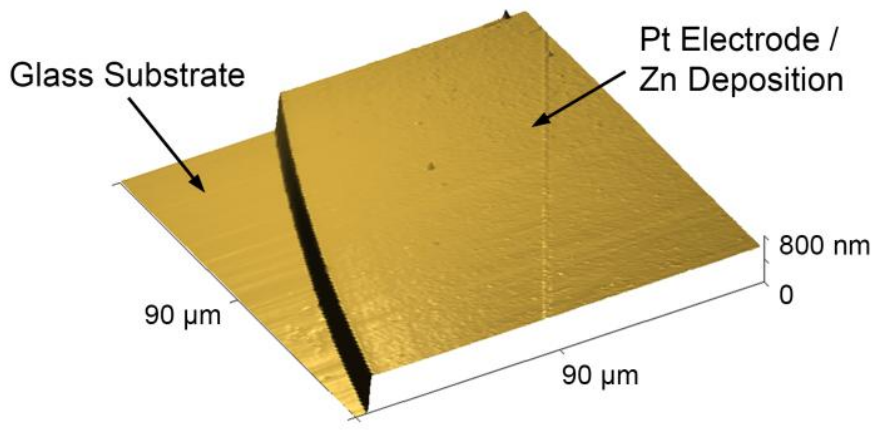

Figure 3

Three-dimensional AFM image of the Pt electrode edge prior to zinc deposition and the underlying glass substrate. The scanning area shown is $90 \mu \mathrm{m} \times 90 \mu \mathrm{m}$.

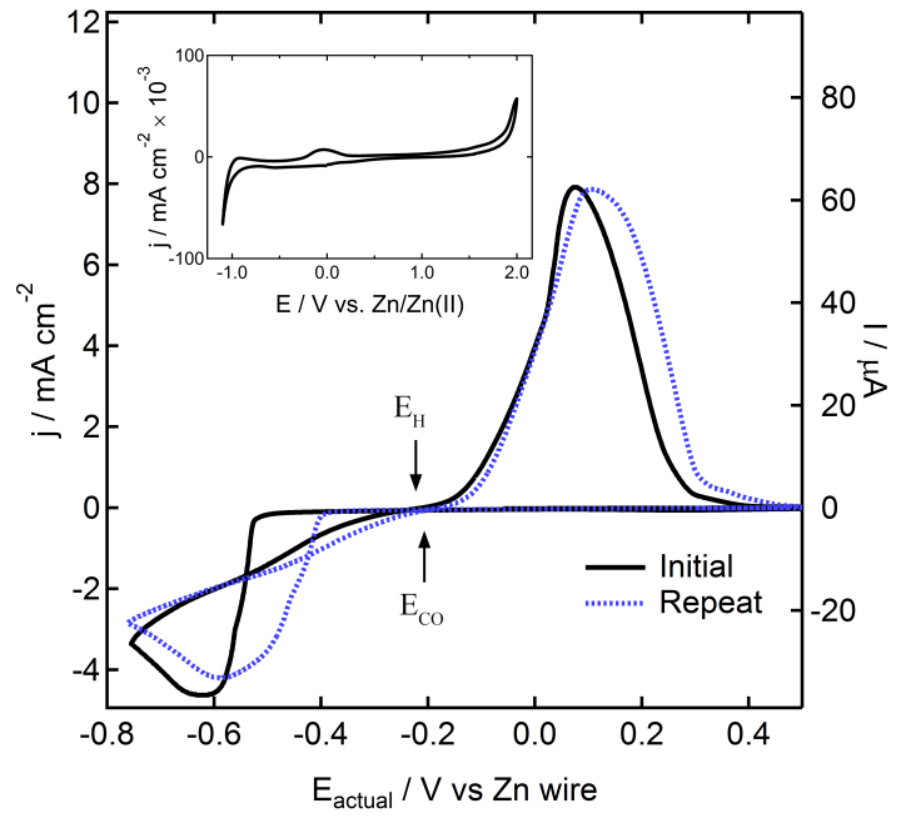

Figure 4

Initial and repeat cyclic voltammograms of a Pt electrode within $0.34 \mathrm{~mol} \mathrm{~kg}^{-1} \mathrm{Zn}(\mathrm{OTf})_{2} / \mathrm{BMIm}$ OTf at a scan rate of $10 \mathrm{mV} \mathrm{s}^{-1}$ at $25^{\circ} \mathrm{C}$. The potential was compensated with the measured solution resistance for the AFM cell. Inset shows cyclic voltammogram of a Pt electrode within neat BMIm OTf at a scan rate of $10 \mathrm{mV} \mathrm{s}^{-1}$ at room temperature. 


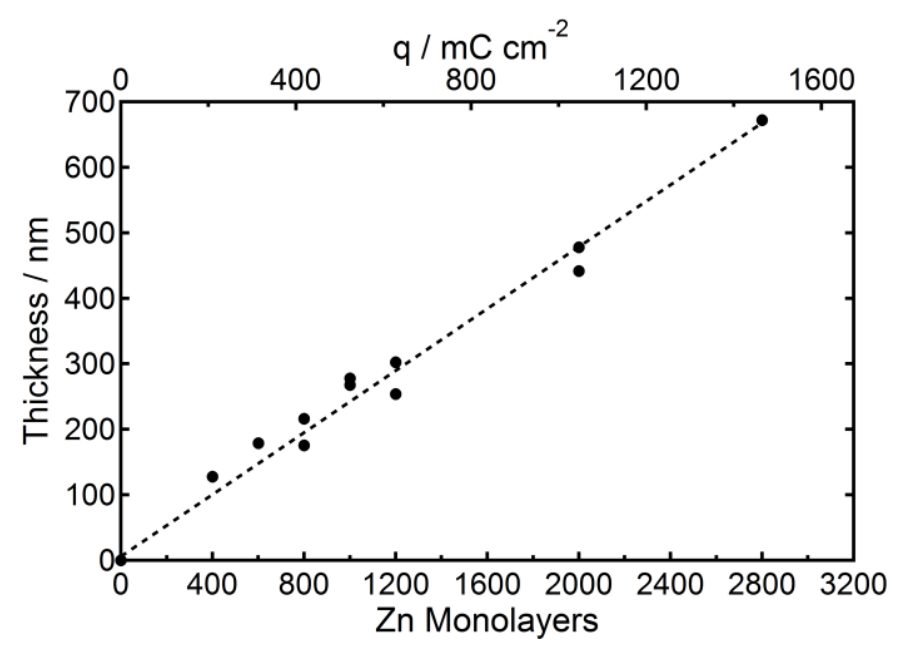

Figure 5

Zinc deposition thickness measured by AFM versus the total amount of charge passed in terms of $\mathrm{Zn}$ monolayers. The dashed line is a best fit line for the data.

(a) $200 \mathrm{ML}$

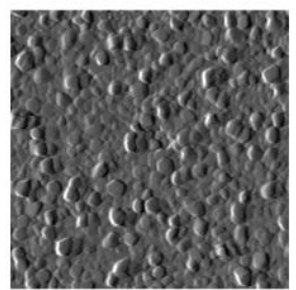

(f) $1200 \mathrm{ML}$

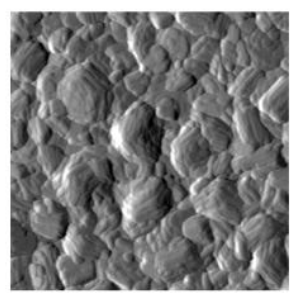

(b) $400 \mathrm{ML}$

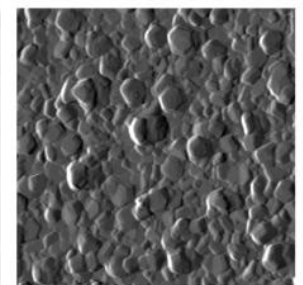

(g) $1600 \mathrm{ML}$

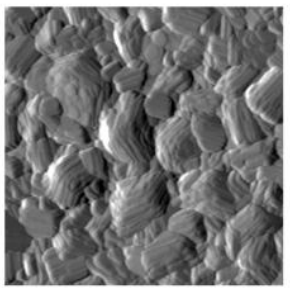

(c) $600 \mathrm{ML}$

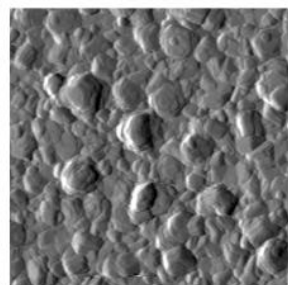

(h) $2000 \mathrm{ML}$

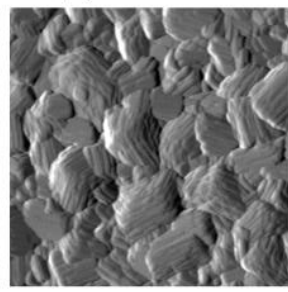

(d) $800 \mathrm{ML}$

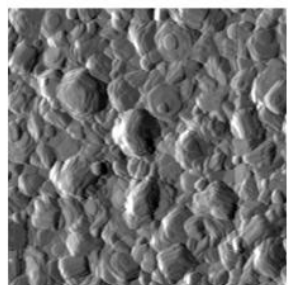

(i) $2400 \mathrm{ML}$

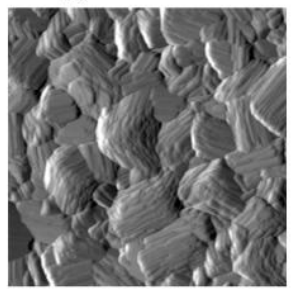

(e) $1000 \mathrm{ML}$

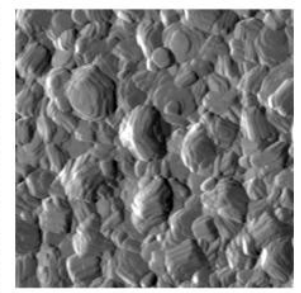

(j) $2800 \mathrm{ML}$

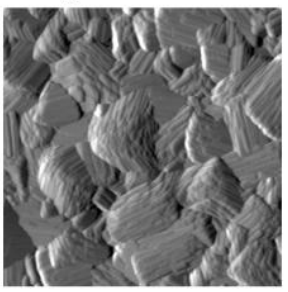

Figure 6

AFM image (deflection) sequence of the zinc surface during electrodeposition within 0.34 mol $\mathrm{kg}^{-1} \mathrm{Zn}(\mathrm{OTf})_{2}$ at deposition overpotentials of $325 \mathrm{mV}$ for various amounts of charge passed per area in terms of $\mathrm{Zn}$ monolayers (ML) where $200 \mathrm{Zn}$ monolayers is equivalent to $104.6 \mathrm{mC} \mathrm{cm}^{-2}$ of charge passed per area. The AFM images are $2 \mu \mathrm{m} \times 2 \mu \mathrm{m}$. 

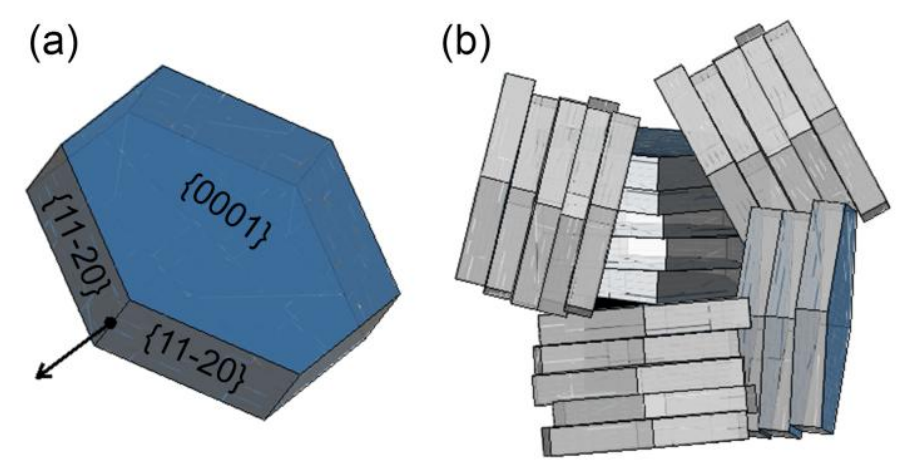

Figure 7

Schematic of zinc plates. a) A single hexagonal plate with the slow growing basal faces, $\{0001\}$, in blue and the faster growing (11-20 prism faces in grey. The intersection of the prism faces (arrow) is the fastest growing edge. The surface morphology evolves to domains of co-aligned platelets with the fast growth direction roughly perpendicular to the interface. b) Top down view of 5 domains schematically shown 


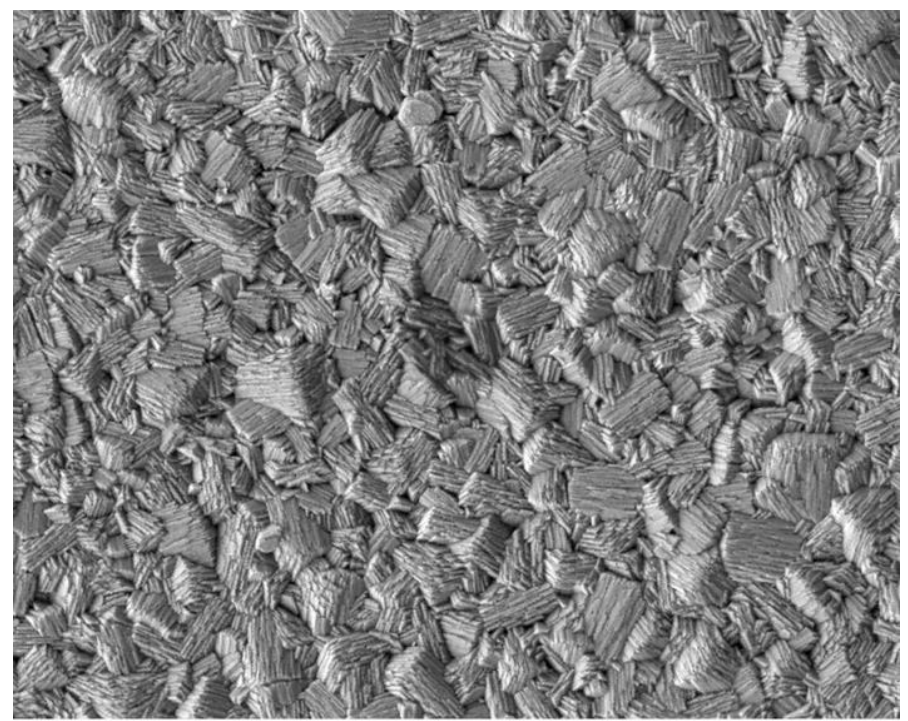

(a)

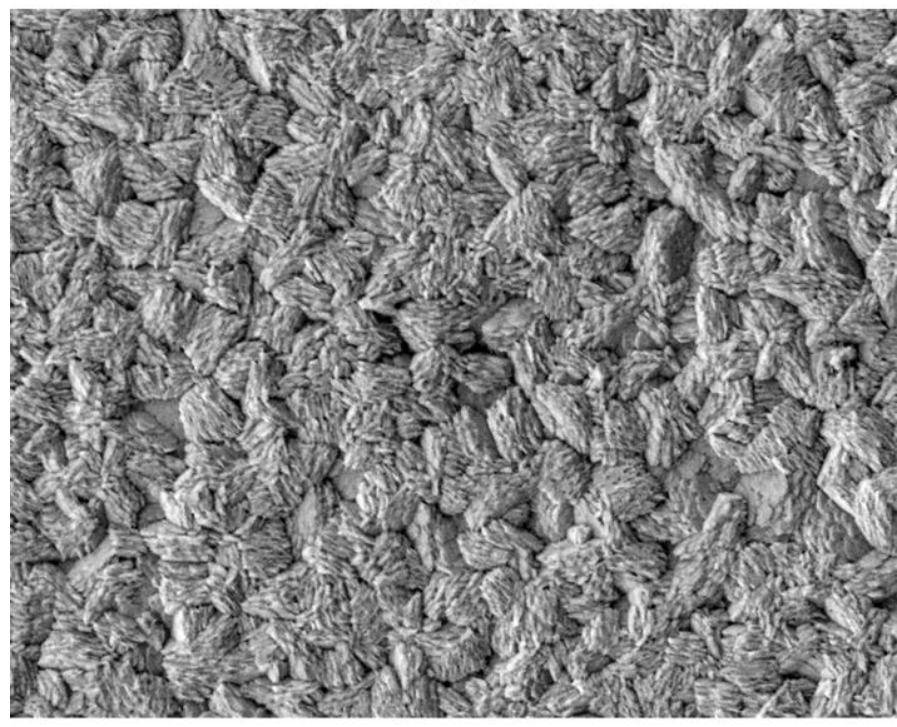

(b)

\section{$1 \mu \mathrm{m}$}

Figure 8

SEM image obtained ex-situ of the zinc deposition after $1465 \mathrm{mC} \mathrm{cm}^{-2}$ of charge passed (2800 $\mathrm{Zn}$ monolayers) within $0.24 \mathrm{~mol} \mathrm{~kg}^{-1} \mathrm{Zn}(\mathrm{OTf})_{2}$ at deposition overpotentials of (a) $325 \mathrm{mV}$ and (b) $445 \mathrm{mV}$. 

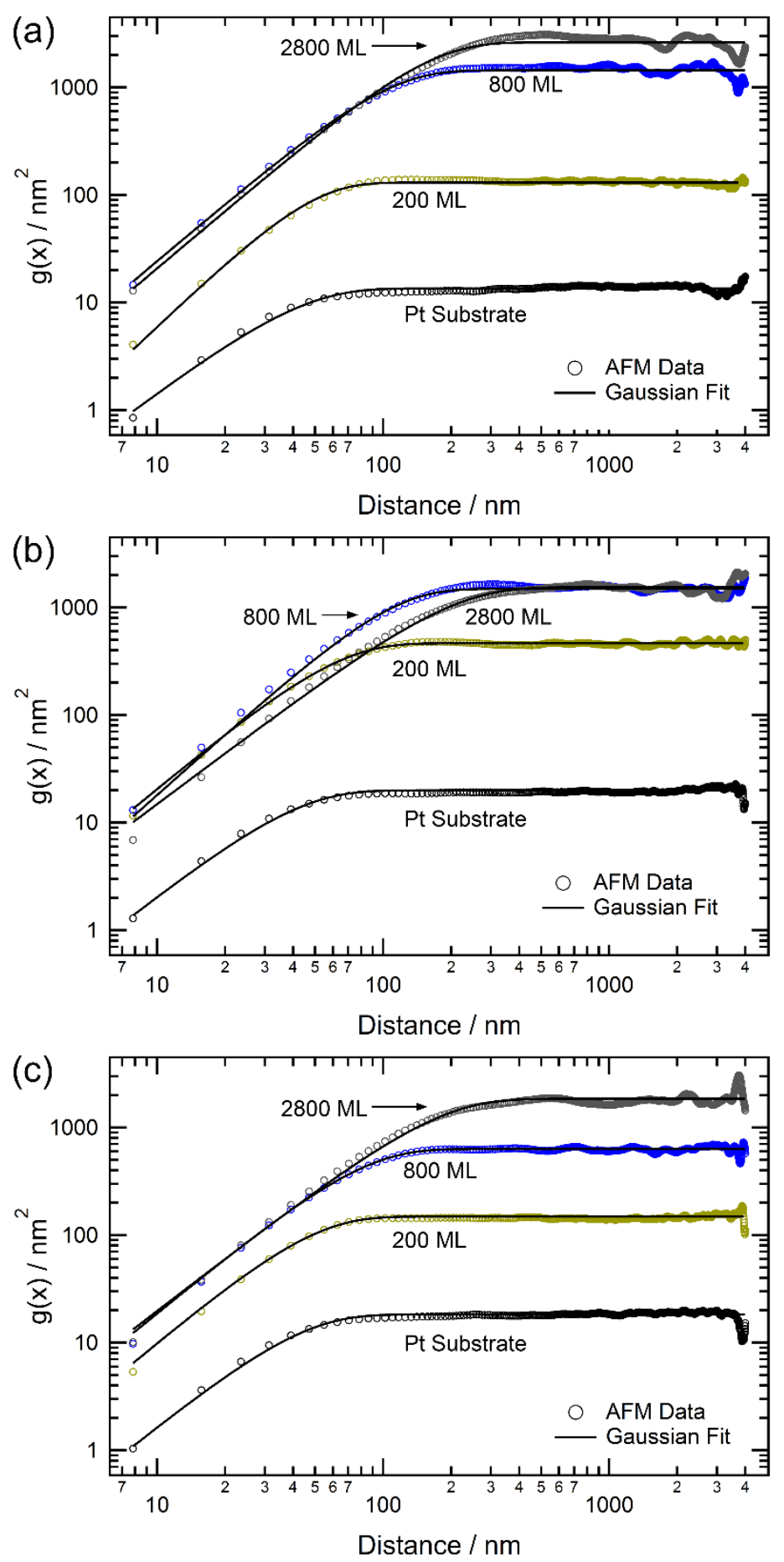

Figure 9.

Selected height difference correlations of the AFM data obtained during zinc deposition within $0.34 \mathrm{~mol} \mathrm{~kg}^{-1} \mathrm{Zn}(\mathrm{OTf})_{2}$ at (a) $245 \mathrm{mV}$, (b) $325 \mathrm{mV}$, and (c) $445 \mathrm{mV}$ overpotential. 

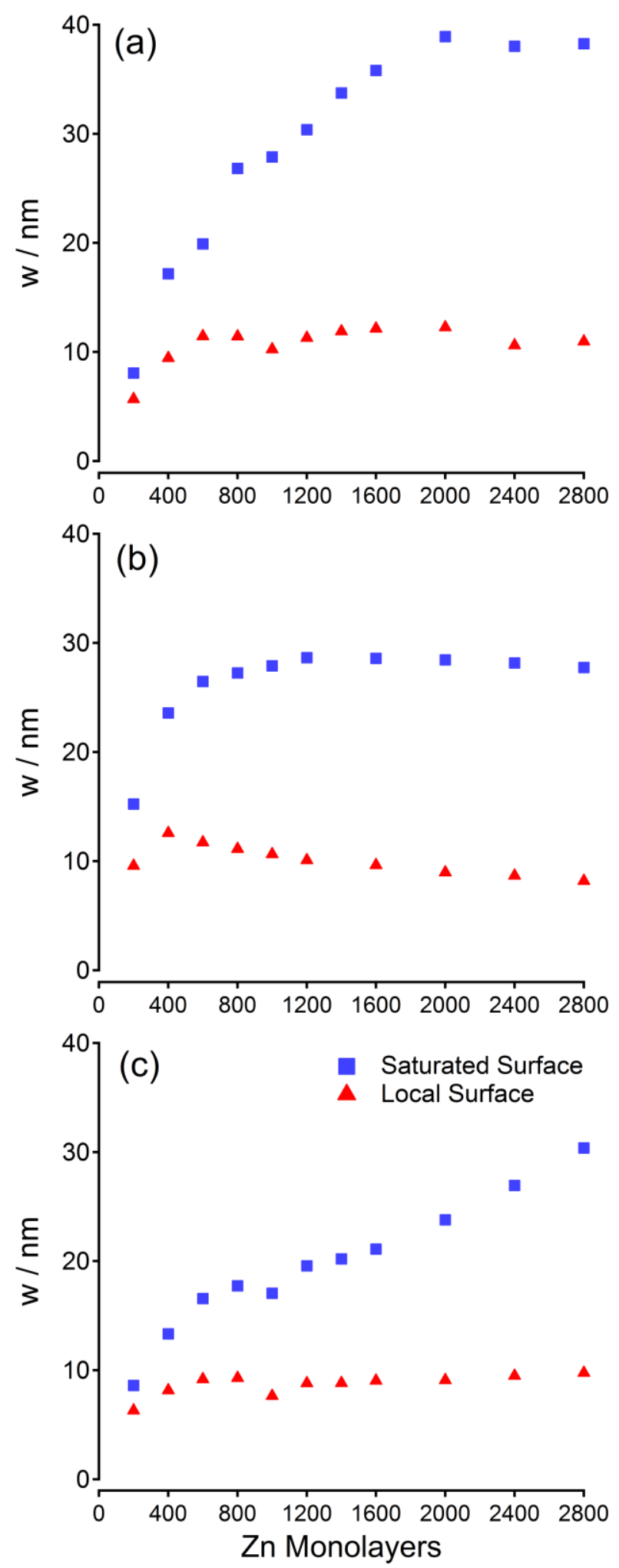

0200400600800100012001400
$q / \mathrm{mC} \mathrm{cm}^{-2}$ 
Figure 10.

Saturated (blue square, $x>\xi$ ) and local (red triangle, $x=40 \mathrm{~nm}$ ) root mean square height difference, $w$, of the zinc surface versus the amount of charge passed per area, $q$, and in $\mathrm{Zn}$ monolayers for deposition within $0.34 \mathrm{~mol} \mathrm{~kg}^{-1} \mathrm{Zn}(\mathrm{OTf})_{2} / \mathrm{BMIm}$ OTf at overpotentials of (a) 245 $\mathrm{mV}$, (b) $325 \mathrm{mV}$, and (c) $445 \mathrm{mV}$.

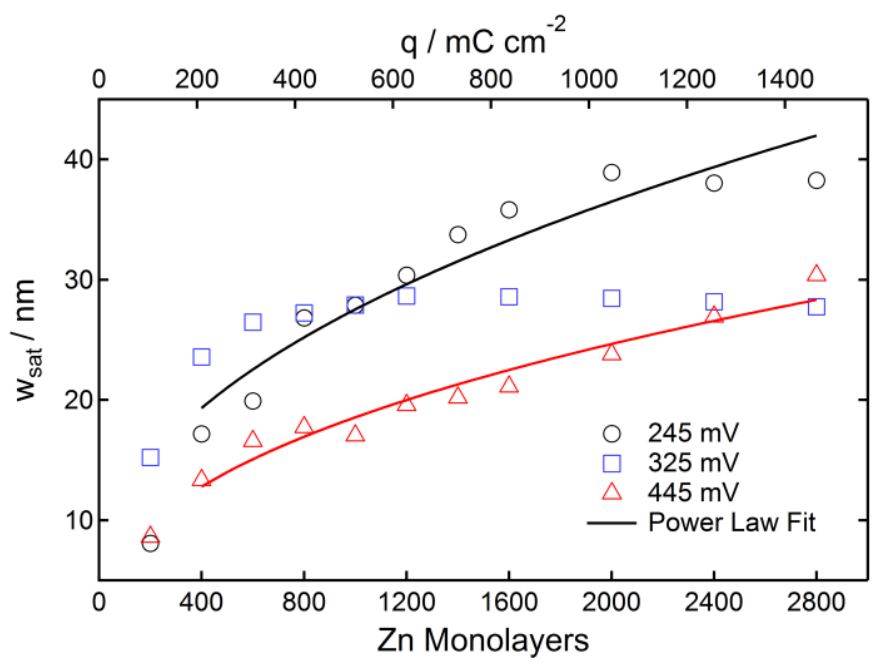

Figure 11.

The saturated surface RMS, $w_{\text {sat }}$, obtained for the zinc deposition as a function of the amount of charge passed in terms of $\mathrm{Zn}$ monolayers. A power law fit for depositions at $245 \mathrm{mV}$ overpotential and $445 \mathrm{mV}$ overpotential is shown as a solid line. 


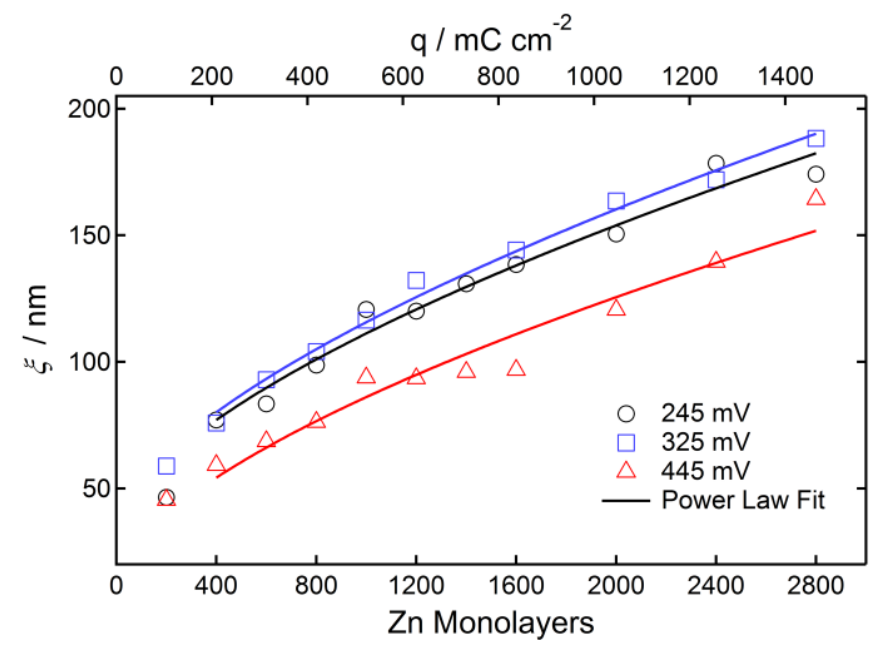

Figure 12.

The lateral correlation length, $\xi$, obtained for the zinc deposition as a function of the amount of charge passed in terms of $\mathrm{Zn}$ monolayers. A power law fit to the data for each deposition condition is shown as a solid line. 


\section{Tables}

Table 1.

Room temperature morphology of zinc deposited from ionic liquids

\begin{tabular}{|c|c|c|c|c|}
\hline Cation* & Anion & Zn source & Film Morphology & Reference \\
\hline BMIm & OTf & $\mathrm{Zn}(\mathrm{OTf})_{2}$ & $\begin{array}{c}\text { Domains of co-aligned, prism- } \\
\text { oriented hexagonal platelets }\end{array}$ & This study \\
\hline BMIm & $\mathrm{Cl}$ & $\mathrm{ZnCl}_{2}$ & Thick faceted crystals & {$[11]$} \\
\hline BMIm & $\mathrm{HSO}_{4}$ & $\mathrm{ZnSO}_{4}$ & $\begin{array}{c}\text { Non-collinear prism-oriented } \\
\text { hexagonal platelets }\end{array}$ & {$[12]$} \\
\hline EMIm & $\mathrm{Cl}$ & $\mathrm{ZnCl}_{2}$ & N/A & {$[13]$} \\
\hline EMIm & OTf & $\mathrm{Zn}(\mathrm{OTf})_{2}$ & $\begin{array}{c}\text { Clusters of non-collinear prism- } \\
\text { oriented crystals }\end{array}$ & {$[14]$} \\
\hline EMIm & Tf2N & $\mathrm{Zn}(\mathrm{Tf} 2 \mathrm{~N})_{2}$ & $\begin{array}{c}\text { Untextured, micron scale thick } \\
\text { facets }\end{array}$ & {$[15]$} \\
\hline EMIm & DCA & $\mathrm{Zn}(\mathrm{DCA})_{2}$ & $\begin{array}{c}\text { Uniform film, fine structure not } \\
\text { described }\end{array}$ & {$[16]$} \\
\hline BMP & DCA & $\mathrm{ZnCl}{ }_{2}$ & Untextured faceted hexagons & {$[17]$} \\
\hline BMP & Tf2N & $\mathrm{ZnCl}{ }_{2}$ & N/A & {$[18]$} \\
\hline BMP & OTf & $\mathrm{Zn}(\mathrm{OTf})_{2}$ & $\begin{array}{c}\text { Small grained, rounded and } \\
\text { disordered hexagonal plates }\end{array}$ & {$[14]$} \\
\hline BMP, MPP & Tf2N & $\mathrm{Zn}(\mathrm{Tf} 2 \mathrm{~N})_{2}$ & Nanometer scale needles & {$[15]$} \\
\hline
\end{tabular}

*BMIm 1-butyl-3-methylimidazolium , EMIm 1-ethyl-3- methylimidazolium, BMP 1-butyl-1-methylpyrrolidinium, MPP 1methyl-1-propyl-pyrrolidinium

Table 2.

Electrodeposition parameters for the AFM investigations

\begin{tabular}{|c|c|c|c|c|}
\hline Test & $E_{\text {applied }}$ & $\begin{array}{c}i R_{u} \\
\text { Avg / Max / Min }\end{array}$ & $E_{C O}$ & $\begin{array}{c}\eta \\
\text { Avg }\end{array}$ \\
\hline & ( $\mathrm{mV}$ vs. $\mathrm{Zn}$ wire) & $(\mathrm{mV})$ & (mV vs. $\mathrm{Zn}$ wire) & $(\mathrm{mV})$ \\
\hline 1 & -400 & $27 / 35 / 7$ & $-130+/-20$ & 245 \\
\hline 2 & -500 & $26 / 34 / 4$ & $-150+/-20$ & 325 \\
\hline 3 & -650 & $75 / 125 / 47$ & $-130+/-20$ & 445 \\
\hline
\end{tabular}


Table 3.

Measured grain size parameters from SEM images and the standard deviation range (SD)

\begin{tabular}{ccc}
\hline $\begin{array}{c}\text { Applied } \\
\text { Overpotential } \\
(\mathrm{mV})\end{array}$ & $\begin{array}{c}\text { Mean Linear } \\
\text { Intercept, } \bar{l} \\
(\mathrm{~nm} \pm \mathrm{SD})\end{array}$ & $\begin{array}{c}\text { Mean Spatial } \\
\text { Radius, } \bar{R} \\
(\mathrm{~nm} \pm \mathrm{SD})\end{array}$ \\
\hline 325 & $255 \pm 7$ & $200 \pm 6$ \\
445 & $241 \pm 22$ & $190 \pm 17$ \\
\hline
\end{tabular}

Table 4.

Fit parameters from the zinc deposition experiments for selected amounts of charge passed (expressed in monolayers, ML, and coulombs per area)

\begin{tabular}{cccccc}
\hline $\begin{array}{c}\text { Deposition } \\
\text { Overpotential } \\
(\mathrm{mV})\end{array}$ & \multicolumn{2}{c}{ Charge Passed } & wsat & $\xi$ & $\alpha$ \\
\hline Substrate & - & - & $2.9 \pm 0.3$ & $39 \pm 3$ & $0.82 \pm 0.03$ \\
245 & 200 & 104.6 & 8.1 & 46.5 & 0.99 \\
245 & 800 & 418.4 & 26.8 & 98.7 & 0.89 \\
245 & 2800 & 1465 & 38.3 & 174 & 0.89 \\
325 & 200 & 104.6 & 15.2 & 58.8 & 0.87 \\
325 & 800 & 418.4 & 27.2 & 104 & 0.94 \\
325 & 2800 & 1465 & 27.8 & 188 & 0.79 \\
445 & 200 & 104.6 & 8.6 & 45.4 & 0.89 \\
445 & 800 & 418.4 & 17.7 & 76.2 & 0.86 \\
445 & 2800 & 1465 & 30.4 & 164 & 0.81 \\
\hline
\end{tabular}

